\title{
Effects of Mineralogy on Sorption of Strontium and Cesium Onto Calico Hills Tuff
}

Manuscript Completed: September 1989

Date Published: April 1990

Prepared by

R. E. Meyer, W. D. Arnold, F. I. Case,

G. D. O'Kelley, J. F. Land

Oak Ridge National Laboratory

Operated by Martin Marieta Energy Systems, Inc.

Oak Ridge National Laboratory

Oak Ridge, TN 37831

Prepared for

Division of Engineering

Office of Nuclear Regulatory Research

U.S. Nuclear Regulatory Commission

Washington, DC 20555

NRC FIN B0462

Under Contract No. DE-AC05-85OR21400 
PREVIOUS REPORTS IN THIS SERIES

January 1983 Valence Effects on Adsorption - A Preliminary Assessment of Valence State Control on

Sorption Measurements, NUREG/CR-2863

February 1984 Valence Effects on the Sorption of Nuclides on Rocks and Minerals, NUREG/CR-3389

February 1985 Valence Effects on the Sorption of Nuclides on Rocks and Minerals. II, NUREG/CR-4114

March 1986

Valence Effects on Solubility and Sorption - The Solubility of Tc(IV) Oxides, NUREG/CR-4309

July 1987

The Solubility of Electrodeposited Tc(IV) Oxides, NUREG/CR-4865

May 1988

Thermodynamic Properties of Tc(IV) Oxides:

Solubilities and the Electrode Potential of the Tc(VII)/Tc(IV)-Oxide Couple, NUREG/CR-5108

June 1989

Thermodynamics of Technetium Related to Nuclear Waste Disposal - Solubilities of Tc(IV) Oxides and the Electrode Potential of the Tc(VII)/Tc(IV) Oxide Couple, NUREG/CR-5235 


\section{DISCLAIMER}

This report was prepared as an account of work sponsored by an agency of the United States Government. Neither the United States Government nor any agency thereof, nor any of their employees, make any warranty, express or implied, or assumes any legal liability or responsibility for the accuracy, completeness, or usefulness of any information, apparatus, product, or process disclosed, or represents that its use would not infringe privately owned rights. Reference herein to any specific commercial product, process, or service by trade name, trademark, manufacturer, or otherwise does not necessarily constitute or imply its endorsement, recommendation, or favoring by the United States Government or any agency thereof. The views and opinions of authors expressed herein do not necessarily state or reflect those of the United States Government or any agency thereof. 


\section{DISCLAIMER}

Portions of this document may be illegible in electronic image products. Images are produced from the best available original document. 
Sorption and desorption measurements were made of strontium and cesium onto clinoptilolite and Calico Hills Tuff. The object was to see whether there was a correlation between sorption of strontium and cesium onto Calico Hills Tuff and the sorption of strontium and cesium onto clinoptilolite based on the content of clinoptilolite in the Calico Hills Tuff. If sorption onto Calico Hills Tuff is solely due to the presence of clinoptilolite, then the ratios of the sorption ratios on tuff to those on clinoptilolite at similar conditions should be the weight fraction of the clinoptilolite on the tuff. Since the tuff contained about 508 clinoptilolite, the ratios would be expected to be about 0.5 if sorption was due solely to clinoptilolite. The experimental evidence showed that the ratios were generally near 0.5 for both cesium and strontium sorption and that ion-exchange processes were operative for both the clinoptilolite and the tuff. However, the ratios differed to a small extent for the different conditions, and there were indications that other sorption processes were involved. 
CONTENTS

ABSTRACT . . . . . . . . . . . . . . . . . . . . . . . . . . iii

LIST OF FIGURES . . . . . . . . . . . . . . . . . . . . . . . . . . vii

LIST OF TABLES. . . . . . . . . . . . . . . . . . . . . . . . . . viii

1. EXECUTIVE SUMMARY . . . . . . . . . . . . . . . . . . . . . . 1

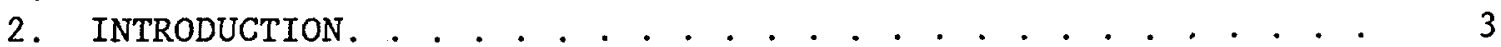

2.1 YUCCA MOUNTAIN DATA . . . . . . . . . . . . . . . . . . . . . 3

2.2 MIXTURES OF MINERALS. . . . . . . . . . . . . . . . . . . . 6

2.3 ION EXCHANGE RELATIONSHIPS. . . . . . . . . . . . . . . . 7

3. EXPERIMENTAL. . . . . . . . . . . . . . . . . . . . . . . . . . . . 8

3.1 ROCK AND MINERAL SAMPLES. • . . . . . . . . . . . . . . . 8

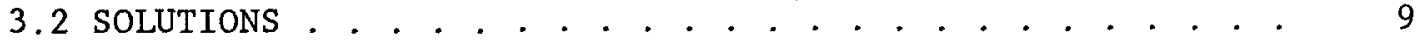

3.3 PROCEDURES. . . . . . . . . . . . . . . . . . . . . . . 10

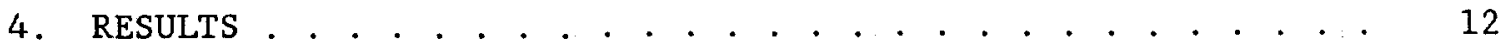

5. DISCUSSION. . . . . . . . . . . . . . . . . . . . . . . . . . . . . 21

6. REFERENCES. . . . . . . . . . . . . . . . . . . . . . 30 


\section{Figure}

1. Sorption and desorption of strontium onto clinoptilolite as a function of contact time . . . . . . . . 14

2. Sorption and desorption of strontium onto Calico Hills Tuff as a function of contact time . . . . . . . 16

3. Sorption and desorption of cesium onto clinoptilolite as a function of contact time. . . . . . . . . 18

4. Sorption and desorption of cesium onto Calico Hills Tuff as a function of contact time . . . . . . . 20

5. Plot of the logarithm of the sorption ratio of strontium on clinoptilolite vs the logarithm of the concentration of $\mathrm{Na}^{+}$. . . . . . . . . . . . . . 22

6. Plot of the logarithm of the sorption ratio of strontium on Calico Hills Tuff vs the logarithm of the concentration of $\mathrm{Na}^{+}$. . . . . . . . . . . . . 23

7. Plot of the logarithm of the sorption ratio of cesium on clinoptilolite vs the logarithm of the concentration of $\mathrm{Na}^{+}$.

8. Plot of the logarithm of the sorption ratio of cesium on Calico Hills Tuff vs the logarithm of the concentration of $\mathrm{Na}^{+}$. . . . . . . . . . . . . 27

9. The ratios of the sorption ratios of strontium on Calico Hills Tuff to the sorption ratios on clinoptilolite as a function of contact time at various concentrations of $\mathrm{Na}^{+}$. . . . . . . . . . . . . 28

10. The ratios of the sorption ratios of cesium on Calico Hills Tuff to the sorption ratios on clinoptilolite as a function of contact time at various concentrations of $\mathrm{Na}^{+}$. 
Table

Page

2.1 Analysis of reference $\mathrm{J}-13$ well water........... 5

4.1 Summary of sorption and desorption results:

Sr sorption on clinoptilolite, at various contact times and $\mathrm{NaCl}$ concentrations, followed by 14-d desorption. . . 13

4.2 Summary of sorption and desorption results:

Sr sorption on Calico Hills Tuff, at various contact

times and $\mathrm{NaCl}$ concentrations, followed by two

14-day desorptions. . . . . . . . . . . . . . . . . 15

4.3 Summary of sorption and desorption results:

Cs sorption on clinoptilolite, at various contact times

and $\mathrm{NaCl}$ concentrations, followed by $14-\mathrm{d}$ desorption.

4.4 Summary of sorption and desorption results:

Cs sorption on Calico Hills Tuff, at various contact

times and $\mathrm{NaCl}$ concentrations, followed by two

14-day desorptions. . . . . . . . . . . . . . . . . . . 19

5.1 Slopes of plots of the logarithms of the concentrations

of the sorbing ion vs the logarithms of the concentrations

of $\mathrm{Na}^{+}$for sorption onto clinoptilolite and Calico

Hills Tuff. 


\section{EFFECTS OF MINERALOGY ON THE SORPTION \\ OF STRONTIUM AND CESIUM \\ ONTO CALICO HILLS TUFF}
R. E. Meyer
W. D. Arnold
F. I, Case
G. D. O'Kelley
J. F, Land

\section{EXECUTIVE SUMMARY}

The sorption properties of tuff formations at the proposed site for the high-level nuclear waste repository at Yucca Mountain, Nevada, have been extensively studied by DOE and reported in a series of quarterly progress reports (e.g., Ogard et al. 1985) and in topical and summary reports (Daniels et al. 1982, Thomas 1987). The collection of these data are the responsibility of the Yucca Mountain Project (YMP), formerly the Nevada Nuclear Waste Storage Investigations (NNWSI).

In an attempt to compare sorption onto various tuffs, correlations of the mineralogy of the tuff samples with sorption data have been investigated and reported (Daniels et al. 1982). Specifically, attempts were made to correlate the sorption ratios with the clinoptilolite content of some of the tuffs that were studied. For cesium, strontium, and barium, the correlation with the amount of clinoptilolite in the tuffs was good considering the uncertainties in the data; for technetium, cerium, europium, and americium there were no obvious trends with zeolite abundance. For uranium, neptunium, and plutonium, there were no trends with increased zeolitization; however sorption ratios were somewhat higher for zeolitized tuffs than for non-zeolitized tuffs.

The DOE attempts at correlation between sorption of cesium, strontium, and barium and the zeolite content of the tuffs have been fairly good considering the uncertainties involved. However, if care is taken to select optimum conditions, a better test of the correlation could be done. The solution used in the sorption tests, J-13 well water, is a dilute solution of $\mathrm{NaHCO}_{3}$ along with silicon in some form and moderate concentrations of other cations and anions, and sorption ratios from this solution tend to be very high because of the small concentrations of cations. It is difficult to determine sorption ratios over about 3000 $\mathrm{L} / \mathrm{kg}$ with precision because almost all of the tracer is removed from the solution, and it is difficult to obtain precision with count rates that are only slightly above background. Unless the solution/solid ratio is increased, which is not the case for the DOE data, there will always be a problem with precise determinations of large sorption ratios. Therefore, to compare sorption data it would be better to use solutions of higher concentrations of competing ions (assuming that ion exchange is the sorption mechanism); for these solutions, sorption ratios will be much lower and thus easier to determine with precision. 
Sorption and desorption measurements were made of strontium and cesium onto clinoptilolite and Calico Hills tuff using solutions of $\mathrm{NaCl}$ containing small concentrations of $\mathrm{NaHCO}_{3}$. The concentrations of $\mathrm{Na}^{+}$were chosen to bring the sorption ratios to a range where they could be determined with reasonable precision. The object was to see whether there was a correlation between sorption of strontium and cesium onto Calico Hills Tuff and the sorption of strontium and cesium onto clinoptilolite based on the content of clinoptilolite in the Calico Hills Tuff. If sorption onto Calico Hills Tuff is solely due to the presence of clinoptilolite, then the ratios of the sorption ratios on tuff to those on clinoptilolite at similar conditions should be the weight fraction of the clinoptilolite on the tuff. Since the tuff contained about 50\% clinoptilolite, the ratios would be expected to be about 0.5 if there was a correlation. The experimental evidence showed the ratios were generally near 0.5 for both cesium and strontium sorption and that ion-exchange processes were operative for both the clinoptilolite and the tuff. However, the ratios differed to a small extent for the different conditions, and there were indications that other sorption processes were involved. 


\section{INTRODUCTION}

\subsection{YUCCA MOUNTAIN DATA}

The sorption properties of tuff formations at the proposed site for the high-level nuclear waste repository at Yucca Mountain, Nevada, have been extensively studied by DOE and reported in a series of quarterly progress reports (e.g., Ogard et al. 1985) and in topical and summary reports (Daniels et al. 1982, Thomas 1987). The collection of these data are the responsibility of the Yucca Mountain Project (YMP), formerly the Nevada Nuclear Waste Storage Investigations (NNWSI). A general review and tabulation of YMP data is given by Tien et al. (1985). Sorption data are also tabulated and discussed in the Environmental Assessment (EA) for the Yucca Mountain site (DOE 1986). Probably the best overall summary is that given by Thomas (1987), which contains all of the batch sorption data for the various tuff samples used; however, it is stated in this report that it contains "an unrefined data set", i.e. some data are included that were obtained during the process of developing the methodology.

The composition of the tuffs at the Yucca Mountain site vary widely, and comparison of sorption properties of tuffs is therefore difficult. To simplify comparison of the tuffs, Thomas (1987) divides the tuffs into four major rock groups: (1) Devitrified (composed primarily of quartz and alkali feldspar), (2) Zeolitized (dominated by an alteration assemblage of zeolites), (3) Glass (high percentage of original glass in sample which is not devitrified or altered to zeolites), and (4) Clays (clays being the major alteration assemblage). Except for the clay group, each of these groups are divided into three subgroups, depending on the relative amounts of clays, zeolites, and glasses. This classification has simplified comparison of sorption behavior to some extent, but there are also wide variations in composition within the various groups and subgroups.

In an attempt to further simplify comparison of sorption onto tuffs, correlations of the mineralogy of the tuff samples with sorption data have been investigated and reported (Daniels et al. 1982). Specifically, attempts were made to correlate the sorption ratios with the clinoptilolite content of some of the tuffs that were studied. For cesium, strontium, and barium, the correlation with the amount of clinoptilolite in the tuffs was fairly good considering the uncertainties in the data; for technetium, cerium, europium, and americium there were no obvious trends with zeolite abundance. For uranium, neptunium, and plutonium, there were no trends with increased zeolitization; however sorption ratios were somewhat higher for zeolitized tuffs than for nonzeolitized tuffs. A correlation is also presented in Daniels et al. (1982) for cesium sorption with total sorptive mineral content; this correlation is also fairly good considering the uncertainties involved. For comparisons of sorption data among different sorbents, experimental conditions must be identical. As discussed below, the use of J-13 well 
water and the techniques used by the YMP are not ideal conditions for comparison of sorption data for different types of tuffs, and therefore correlations might have been better if the conditions had been better.

Most of the reported YMP data were taken from batch sorption experiments done in air using well water from drill hole J-13. Because the composition of the well water may change somewhat over time, a reference composition was selected based upon a number of analyses (Daniels et al. 1982). The composition of this reference well water is given in Table 2.1. The anions were determined by anion chromatography, and the other elements were determined by emission spectroscopy. Except for silicon, aluminum, and iron, the elements in the first portion of the table are most probably present as cations. The predominant cation in J-13 well water is $\mathrm{Na}^{+}$with smaller concentrations of $\mathrm{Ca}^{2+}, \mathrm{K}^{+}$, and other cations. Aluminum and iron are probably present in hydrolyzed forms, possibly partly or wholly as polymeric or very small colloidal material. The predominant anion is $\mathrm{HCO}_{3}{ }^{-}$with lower concentrations of $\mathrm{SO}_{4}{ }^{2-}, \mathrm{NO}_{3}{ }^{-}, \mathrm{Cl}^{-}$, and other anions. J-13 well water also contains considerable silicon, 31 $\mathrm{mg} / \mathrm{L}$ measured as silicon; the chemical form of the silicon is not given, but it could be present as a form of silicic acid or as a colloid. The $\mathrm{pH}$ of well water is 7.1 because of the presence of carbonic acid. Exposure of J-13 to air always resulted in an increase in $\mathrm{pH}$ to values above 8 because of loss of $\mathrm{CO}_{2}$ to the air. Most of the DOE data listed in Thomas (1987) was taken in air, but a small amount of the DOE data was taken in the presence of an overpressure of $\mathrm{CO}_{2}$ to maintain the $\mathrm{pH}$ at a value of approximately 7 .

The DOE attempts at correlation between sorption of cesium, strontium, and barium and the zeolite content of the tuffs have been fairly good considering the uncertainties involved. However, if care is taken to select optimum conditions, a better test of the correlation could be done. As shown in Table 2.1, the solution used, J-13 well water, is a dilute solution of $\mathrm{NaHCO}_{3}$ along with silicon in some form and moderate concentrations of other cations and anions, and sorption ratios from this solution tend to be very high because of the small concentrations of cations. It is difficult to determine sorption ratios over about 3000 $\mathrm{L} / \mathrm{kg}$ with precision because almost all of the tracer is removed from the solution, and it is difficult to obtain precision with count rates that are only slightly above background. Unless the solution/solid ratio is increased, which is not the case for the DOE data, there will always be a problem with precise determinations of large sorption ratios. Therefore, to compare sorption data it would be better to use solutions of higher concentrations of competing ions (assuming that ion exchange is the sorption mechanism); for these solutions, sorption ratios will be much lower and thus easier to determine with precision. 
Table 2.1 Analysis of reference J-13 well water

Constituent

sodium

silicon

calcium

potassium

magnesium

lithium

strontium

iron

aluminum

barium $\mathrm{mg} / \mathrm{L}$

51

31

14

4.9

2.1

0.05

0.05

0.04

0.03

0.003

$\mathrm{meq} / \mathrm{L}$

2.2

4.3

0.7

0.13

0.17

0.007

0.001

0.002

0.003

0.00004

Anions

$$
\begin{aligned}
& \mathrm{HCO}_{3}{ }^{-} \\
& \mathrm{SO}_{4}{ }^{2-} \\
& \mathrm{Cl}^{-} \\
& \mathrm{NO}_{3}{ }^{-} \\
& \mathrm{PO}_{4}{ }^{3-}
\end{aligned}
$$

$\mathrm{pH}$
120

22

7.5

5.6

0.12

7.1
1.97

0.46

0.21

0.09

0.004

Another consideration is the method used by DOE to prepare the groundwater. Their method is to equilibrate the groundwater with tuff for two weeks, filter the groundwater, and then add tracer. The traced solution is then added to a fresh sample of tuff which has also been preequilibrated with J-13. During the preequilibration period, the solution may change in composition and $\mathrm{pH}$, and unless the solution is analyzed before and after every determination, the starting and ending compositions are unknown. Although the changes in solution composition may not be great, they could be large enough to cause significant changes in the sorption ratio, and they would likely be different for different tuffs. In tests to compare sorption ratios among different sorbents, it is important to keep the solution compositions identical for each test. To do this, it is better to equilibrate the rock or mineral with the solution to be used in the sorption equilibration a number of times until the groundwater composition does not change significantly with further equilibrations. 


\subsection{MIXTURES OF MINERALS}

Since rocks are composed of nixtures of minerals, it is helpful to inquire what the relationship is between sorption on mixtures and sorption on the individual minerals. The sorption ratio $\left(R_{s}\right)$ is defined as the concentration of a sorbed substance on the sorbent divided by its concentration in the liquid after an experiment to determine sorption. Similarly, the desorption ratio $\left(R_{d}\right)$ is defined the same as the sorption ratio except that it is determined in a desorption experiment. If $R_{s}=R_{d}$ for the same experiment, so that the sorption-desorption reaction is at equilibrium, the term $\mathrm{Kd}$, the equilibrium distribution coefficient, is often used and under these equilibrium conditions, $R_{s}=R_{d}=K d$. For $a$ mixture of minerals or a rock, sorption and desorption ratios can be defined similarly as the total amount of sorbed substance on all of the minerals divided by the total weight of the minerals (effectively the weighted average concentration) divided by the concentration in the solution as shown by Eqs. 2.1-2.3.

$$
\begin{aligned}
\mathrm{Kd} & =\left[\Sigma \mathrm{n}_{i} / \Sigma w_{i}\right] / \mathrm{C} \\
& =\Sigma w_{i} \mathrm{Kd}_{\mathbf{i}} / \mathrm{W} \\
& =\Sigma \mathrm{f}_{\mathbf{i}} \mathrm{Kd}_{\mathrm{i}}
\end{aligned}
$$

where $n_{i}$ are the amounts of the sorbed substance on the individual minerals, $w_{i}$ are the weights of the minerals, $\mathrm{Kd}_{\mathrm{i}}$ are the equilibrium distribution coefficients of the individual minerals, $f_{1}$ are the weight fractions of the minerals, and $\mathrm{C}$ is the concentration of the sorbing material in the solution. Thus, the overall distribution coefficient is the sum of the weight fractions of the minerals times their respective distribution coefficients. One of the problems in using Eq. 2.3 is the determination of the sorption ratios of the individual sorbents in the mixture. Using sorption ratios determined with the individual minerals in Eq. 2.3 implies the assumption that sorption ratios measured with individual minerals are identical to those for a mixture. As discussed below, this may not necessarily be so because various types of interactions could occur anong the components of a mixture while in contact with the solution.

Although there have been innumerable studies of sorption on natural mixtures such as rocks and soils, there have been to our knowledge only a very few where the mixture has been analyzed and sorption studied on components of the mixture. Triolo and Lietzke (1979) presented the results of calculations concerning what one would expect from sorption isotherms for various mixtures; however, no experimental work was given. Bunzl and Schultz (1980) have shown ideal behavior for sorption of lead on mixtures of bentonite and peat.

Sorption on binary mixtures have been studied by Palmer et al. (1981) for 
a number of mixtures of well characterized minerals. In some cases, Eq. 2.3 could adequately account for the overall distribution coefficient of the mixtures, and in other cases deviations were observed. Both positive and negative deviations were observed. Because Eq. 2.3 follows directly from the definition of the sorption ratio (or distribution coefficient), it must be valid for cases where there are no interactions among the minerals and where experimental conditions are identical for measurements with the individual minerals and with the mixtures or rock. Since deviations were observed by Palmer et al., either there were interactions among the tested minerals or there were experimental difficulties. Some of the deviations from Eq. 2.3 given in Palmer et al. (1981) suggest interactions between the components of the binary mixtures. Experiments to compare results between individual minerals and mixtures must be done under identical conditions. If there is a dependence of sorption ratio on the concentration of the nuclide in the solid, $i$. e. a non-linear sorption isotherm, then comparison must be made at the same point on the isotherm for the individual mineral and the mixture. Further, if sorption is dependent on surface area rather than weight, then the individual sorption ratios would have to be weighted by the surface area of the sorbents.

Although a rock is composed of a number of mineral phases, it is possible that there are interactions among the phases. Analysis by $\mathrm{X}$-ray diffraction, which is sensitive to bulk composition, would not normally show differences in the surfaces, and it is quite possible that the surfaces may be altered. However, if sorption is sensitive to the total weight of the sorbent, it should not matter greatly, except perhaps for kinetics, if the surfaces are altered. Thus, to test Eq. 2.3 for tuffs it is best to begin with relatively "simple" sorbents such as minerals that are known to be ion exchangers that sorb ions in the bulk of the mineral. For that reason we selected Calico Hills Tuff, which is a friable tuff that is composed of over 508 clinoptilolite, a zeolite. The principal sorbing mineral is expected to be clinoptilolite. None of the other components of Calico Hills Tuff are expected to sorb $\mathrm{Cs}^{+}$and $\mathrm{Sr}^{2+}$ significantly, i.e. the values of $\mathrm{Kd}_{\mathrm{i}}$ for the other components are expected to be essentially zero. Under these conditions, Kd(Calico Hills Tuff) = $f_{i} K d(c l i n o p t i l o l i t e)$, and the ratio of $K d$ (or $R_{s}$ ) for the tuff to that of clinoptilolite should simply be equal to the weight fraction of clinoptilolite.

Comparisons of sorption on tuffs and component minerals can be helped if the sorbents are brought as nearly as possible to the same initial conditions. This can be done by keeping the solution compositions relatively simple, and then pretreating the sorbents a number of times with the solution before the tracer is added.

\subsection{ION EXCHANGE RELATIONSHIPS}

If ion exchange is the dominant sorption mechanism on a mineral or rock, then equilibrium relations among the various reactants should be observed. 
Assuming equilibrium and neglecting effects of activity coefficients, the following relations describes an ion exchange reaction:

$$
\begin{aligned}
& \mathrm{mM}^{\mathrm{n}+}{ }_{\mathrm{aq}}+\mathrm{nA}^{\mathrm{mt}}{ }_{\mathrm{ads}}=\mathrm{mM}^{\mathrm{n}+}{ }_{\mathrm{ads}}+\mathrm{nA}^{\mathrm{mt}}{ }_{\mathrm{aq}} \\
& K_{m a}=\frac{\left[M^{n+}\right]^{m}{ }_{a d s}\left[A^{m+}\right]^{n}{ }_{a q}}{\left[M^{n+}\right]^{m}{ }_{a q}\left[A^{m+}\right]^{n}{ }_{a d s}}
\end{aligned}
$$

where $M$ and $A$ are ions of charge $n+$ and $m+$ respectively. The subscript "aq" indicates the aqueous phase and "ads" indicates the ions in the sorbent. The term $\mathrm{K}_{\operatorname{ma}}$ is the equilibrium constant for ion exchange. For the case of trace quantities of $\mathrm{M}^{\mathrm{n}+}$ and an exchanger of capacity $C$, the amount of $\mathrm{A}^{\mathrm{mt}}$ adsorbed (in equivalents) is virtually equal to $\mathrm{C}$. Thus $\mathrm{Eq}$. 2.5 can rewritten

$$
\mathrm{Kd}_{\mathrm{M}}=\mathrm{K}_{\mathrm{ma}}(\mathrm{C} / \mathrm{m})^{\mathrm{n}} /\left[\mathrm{A}^{\mathrm{m+}}\right]^{\mathrm{n}}{ }_{\mathrm{aq}}
$$

Equation 2.6 can be differentiated to give

$$
\left(d \log K d_{M}\right) /\left(d \log \left[A^{m+1}\right]_{a q}\right)=-n / m
$$

Thus under the assumed conditions, a plot of $\log \mathrm{Kd}_{\mathrm{M}}$ vs $\log$ of the concentration of the ion present in large quantities should be linear with a slope equal to $-\mathrm{n} / \mathrm{m}$. For the cases described in this report, the exchange of trace $\mathrm{Sr}^{2+}$ with $\mathrm{Na}^{+}$should have a slope of $-2 / 1$ or -2 and for exchange of $\mathrm{Cs}^{+}$with $\mathrm{Na}^{+}$, the slope should be -1 . Experiments of this type are tests of whether an ion-exchange mechanism is operative in the sorption reaction. For concentrated solutions, activity coefficient corrections may be substantial and deviations might be observed from Eq. 2.7 if a large range of ionic strengths is investigated.

\section{EXPERIMENTAL}

In the experiments described here, strontium and cesium sorption and desorption were determined on Calico Hills Tuff and clinoptilolite, the principal sorbing mineral in this tuff. The solutions used were $\mathrm{NaCl}$ solutions of various concentrations with a small amount of $\mathrm{NaHCO}_{3}$. An overpressure of $\mathrm{CO}_{2}$ was maintained above the samples, which were kept in an atmosphere box during the determinations. To determine the mechanism of sorption, these experiments were done as a function of $\mathrm{NaCl}$ concentration, and one desorption experiment was done after each sorption experiment with clinoptilolite and two successive desorption experiments were done after each sorption experiment for the tuff.

\subsection{ROCK AND MINERAL SAMPLES}


The tuff used in this work was a core section of Calico Hills Tuff from well USW-G1, 1474.8-1476.0 ft. This tuff was characterized by semiquantitative X-ray diffraction and petrographic analyses at the University of Utah Research Institute (UURI). The analytic techniques employed and the results of the characterization are described in UURI report ESL85026-RTR entitled "Petrographic Evaluation of Five Felsic Tuff Samples from Yucca Mountain Nevada Test Site." The full text of this report appears as the Appendix to Meyer et al. (1987).

Analyses of a chip section of the Calico Hills core gave the following composition: 48 quartz, 78 cristobalite, 178 alkali feldspar, 57.8 clinoptilolite, 2(?) mordenite, 38 illite and mica, and 108 amorphous or below detection limit. It is a pumice-rich, non-welded, devitrified tuff. Since only a chip section was analyzed, it is possible that the ground sample that we used varies somewhat from this analysis. A qualitative $X-$ ray diffraction analysis of the ground material used in the sorption tests showed the presence of clinoptilolite, quartz, cristobalite, and feldspars, with the major mineral present being clinoptilolite as was observed with the chip section.

This core sample was ground to $<200$ um by techniques described previously (Meyer et al. 1986, Meyer et al. 1987).

The clinoptilolite was a sample of Hector Clinoptilolite which was ground and sieved to a range of $45-150$ um and then submitted for $X$-ray diffraction analysis. It is difficult to determine the exact purity of this sample but only a few lines of low intensity in the spectrum were found not to coincide with lines for clinoptilolite. Thus, it is possible that it is in the range of 90 to 958 pure. As received, a loss of about 58 by weight, presumably water loss, is found upon heating at $110^{\circ}$ for three days. Sorption ratios presented in this report are corrected for this 58 loss of water, and the values were calculated for dry clinoptilolite.

\subsection{SOLUTIONS}

The solutions used were selected to test whether or not an ion-exchange mechanism was applicable to sorption on both the tuff and the clinoptilolite. As discussed above, sorption ratios above approximately $3000 \mathrm{~L} / \mathrm{kg}$ cannot be determined with great precision and as the values increase the precision of the measurement continuously decreases because so much tracer is removed from the solution. Because zeolites tend to have very high sorption ratios for cesium and strontium, the solution concentrations were selected to provide sufficient $\mathrm{Na}^{+}$to compete with the sorbing ions enough to lower the sorption ratios to a range where they could be measured with precision.

The solutions selected were 2-mol/L, 1-mol/L, and $0.2-\mathrm{mol} / \mathrm{L} \mathrm{NaCl}$, each also containing $0.0035-\mathrm{mol} / \mathrm{L} \mathrm{NaHCO}_{3}$. The solutions were stored and the 
experiments were performed in an atmosphere box containing air and enough $\mathrm{CO}_{2}$ (1.58) to maintain the $\mathrm{pH}$ at approximately 7 . These conditions were found in initial experiments to keep the sorption ratios to values that could be determined with reasonable precision.

The tracers used were ${ }^{85} \mathrm{Sr}$ (half-1ife $64.84 \mathrm{~d}, 514.0-k e v$ gamma ray) and ${ }^{137} \mathrm{Cs}$ (half-life $30.17 \mathrm{y}, 661.6 \mathrm{kev}$ gamma ray). The initial concentration of the strontium was approximately $10^{-12} \mathrm{~mol} / \mathrm{L}$ and that of cesium was $5 \times 10^{-9} \mathrm{~mol} / \mathrm{L}$. The latter was attained by adding dead cesium to the solution along with the tracer; this was done because in our experience results with very small concentrations of cesium often are unreliable. The concentrations of strontium and cesium were considerably smaller at the end of the sorption experiment; the exact concentration depended on the sorption or desorption ratio.

\subsection{PROCEDURES}

All sorption experiments were done by the batch method. In this procedure, $0.2 \mathrm{~g}$ of the solid, either tuff or clinoptilolite, was added to $2 \mathrm{~mL}$ of the test solution and equilibrated for the indicated periods of time. Before use, the soljds were preequilibrated four times. The first preequilibration was carried out with the most concentrated solution, that containing $2-\mathrm{mol} / \mathrm{L} \mathrm{NaCl}$ and $0.0035-\mathrm{mol} / \mathrm{L} \mathrm{NaHCO}_{3}$, to begin conversion of the solids to the sodium form. Then the solids were preequilibrated three times with the solution to be used in the final test. Each preequilibration was done for a period of approximately three days. After each but the final preequilibration, the solution was centrifuged, the solution was decanted, and $2 \mathrm{~mL}$ of fresh solution was added. After centrifugation and decantation in the final preequilibration, the wet solid sample was weighed and enough solution was added to make the volume $1 \mathrm{~mL}$. To that, $1 \mathrm{~mL}$ of traced solution was added to make the final volume $2 \mathrm{~mL}$. The $\mathrm{pH}$ was measured after each preequilibration and after the test period to ensure that the $\mathrm{pH}$ remained at approximately 7 . All samples were weighed after each preequilibration, sorption test, and desorption test to detect any solution leakage.

After the sorption equilibration period, the tube containing the solid was centrifuged for 30 min at 9,000 rcf using a Sorvall RC5B refrigerated centrifuge with a SM24 rotor. As much as possible of the solution was removed with a transfer pipette and put into a second centrifuge tube, which was then centrifuged for $15 \mathrm{~min}$ with a clinical centrifuge. This second centrifugation was done because occasionally small amounts of solid were transferred during the removal of the solution after the first centrifugation. One $\mathrm{mL}$ of the solution was removed for counting, and the remainder was used for $\mathrm{pH}$ measurement. The sorption ratios were then calculated from the loss of tracer from the solution; it was assumed that tracer removed from solution was on the solid. Control samples were carried along with the samples and counted to insure that there was no losses of cesium or strontium from the solutions when there was no solid present. After the end of the sorption part of the experiment, enough 
untraced solution was added to the wet solid remaining in the test tube to make up the volume to two $\mathrm{mL}$, and a desorption experiment was begun. Each desorption experiment was equilibrated for 14 days. For the tuff, a second desorption experiment was carried out after the first desorption experiment. At the end of the desorption periods, the solutions were separated by centrifugation as described above and one $\mathrm{mL}$ samples counted.

All data for all of the preequilibrations, the sorption, and the desorption portions of the experiment were entered into a Lotus 1-2-3 spread sheet, and the sorption and desorption ratios were calculated from formulas entered into the spread sheet. 


\section{RESULTS}

The results of strontium and cesium sorption onto clinoptilolite and Calico Hills tuff are shown in Tables $4.1-4.4$. The data are graphed as a function of time in Figs. 1-4.

For strontium sorption onto clinoptilolite and Calico Hills tuff, the sorption ratios increase with time up to 14 days, especially for the tuff; however, they appear to be approaching a constant value. For desorption of strontium from clinoptilolite, the desorption ratios are all about the same for each concentration (each is a 14-day determination), and on the graphs they are shown as single (filled) points averaged from the five points shown in Table 4.1. For clinoptilolite, it appears that the desorption ratios are only slightly larger than the sorption ratios at 14 days for the $2.00-$ and $1.00-\mathrm{mol} / \mathrm{L} \mathrm{NaCl}$ solutions and slightly smaller for the $0.2-\mathrm{mol} / \mathrm{L} \mathrm{NaCl}$ solution, suggesting that the sorption reaction on clinoptilolite is essentially at equilibrium. For the tuff data shown in Table 4.2, the 14-day desorption data are plotted to correspond with the time of sorption, and the desorption ratios for most cases are slightly higher than those observed for sorption. Also for the tuff, the first 14day desorption ratios are slightly larger than the corresponding sorption ratios for the 2.00 - and the $1.00-\mathrm{mol} / \mathrm{L} \mathrm{NaCl}$ solutions and slightly smaller for the $0.2-\mathrm{mol} / \mathrm{L} \mathrm{NaCl}$ solution. The differences in sorption and desorption ratios for tuff seem to be somewhat higher for tuff than for clinoptilolite, and there may be a non-equilibrium component to the sorption reaction. To study this further, second 14-day desorption experiments were carried out, and in this case the desorption ratios for $2.00-$ and $1.00-\mathrm{mol} / \mathrm{L}$ solutions were approximately the same for all of the conditions, ranging from 50.12 to $87.92 \mathrm{~L} / \mathrm{kg}$, but most importantly they are significantly larger than the first 14 -day desorption ratios. For the $0.20-\mathrm{mol} / \mathrm{L}$ solution, there appears to be no significant difference between the first and second desorption ratios; however, the standard deviations are much larger, and therefore it is difficult to see whether there is a trend.

For cesium sorption onto clinoptilolite, as shown in Table 4.3 and Fig. 3 , the sorption reaction appears to reach equilibrium in a few days; however, the desorption ratios are somewhat larger than the corresponding sorption ratios for the 2.00 - and $1.00-\mathrm{mol} / \mathrm{L}$ solutions. The precision of the data for the $0.2 \mathrm{~mol} / \mathrm{L}$ solution, is not large enough to determine a trend. In contrast to the strontium data, the cesium sorption ratios and first 14-day desorption ratios for Calico Hills Tuff appear to be about the same, and the second desorption ratios are not significantly larger than the corresponding first desorption ratios (Table 4.4 and Fig. 4). 
Table 4.1. Summary of sorption and desorption results:

$\mathrm{Sr}$ sorption on clinoptilolite, at various contact times and $\mathrm{NaCl}$ concentrations, followed by 14-day desorption

\begin{tabular}{lllllll}
\hline \multirow{2}{*}{$\begin{array}{c}\text { Contact } \\
\text { Time }\end{array}$} & \multicolumn{5}{c}{$\begin{array}{l}\text { Sorption Ratio Rs, at } \\
\text { NaC1 Concentration }(\mathrm{mol} / \mathrm{L})\end{array}$} \\
\cline { 2 - 7 } (d) & 2.00 & Sdev & 1.00 & Sdev & 0.20 & Sdev \\
\hline 0.25 & 12.35 & 0.14 & 42.55 & 0.56 & 922.0 & 58.1 \\
1.00 & 15.55 & 0.02 & 51.96 & 0.69 & 1145.9 & 86.9 \\
4.00 & 17.50 & 0.04 & 58.03 & 1.00 & 1313.4 & 101.0 \\
7.00 & 18.12 & 0.41 & 58.92 & 1.80 & 1247.6 & 44.9 \\
14.00 & 18.52 & 0.36 & 60.33 & 0.40 & 1271.1 & 23.0 \\
\hline
\end{tabular}

\begin{tabular}{lllllrr}
\hline Contact & \multicolumn{7}{c}{$\begin{array}{l}\text { 14-Day Desorption Ratio Rd, } \\
\text { at } \mathrm{NaCl} \text { Concentration }(\mathrm{mol} / \mathrm{L})\end{array}$} \\
\cline { 2 - 7 } $\begin{array}{l}\text { Time } \\
\text { (d) }\end{array}$ & 2.00 & Sdev & 1.00 & Sdev & 0.20 & Sdev \\
\hline 0.25 & 20.65 & 0.59 & $63.51^{*}$ & 0.21 & 958.0 & 16.1 \\
1.00 & 20.24 & 0.57 & 62.75 & 0.76 & 1287.6 & 188.8 \\
4.00 & 20.72 & 0.30 & 59.54 & 5.92 & 990.3 & 54.8 \\
7.00 & 20.31 & 0.68 & 61.81 & 1.17 & 1206.9 & 120.7 \\
14.00 & 20.22 & 1.04 & 64.29 & 1.57 & 1142.8 & 132.5 \\
\hline
\end{tabular}

* Average of two samples. One sample was rejected because of a leak. 


\section{Sr Sorption on Clinoptilolite} Effect of Contact Time and $\mathrm{Na}^{+}$Concentration

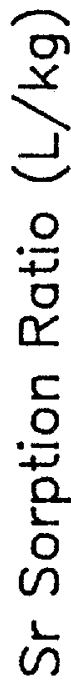

1000

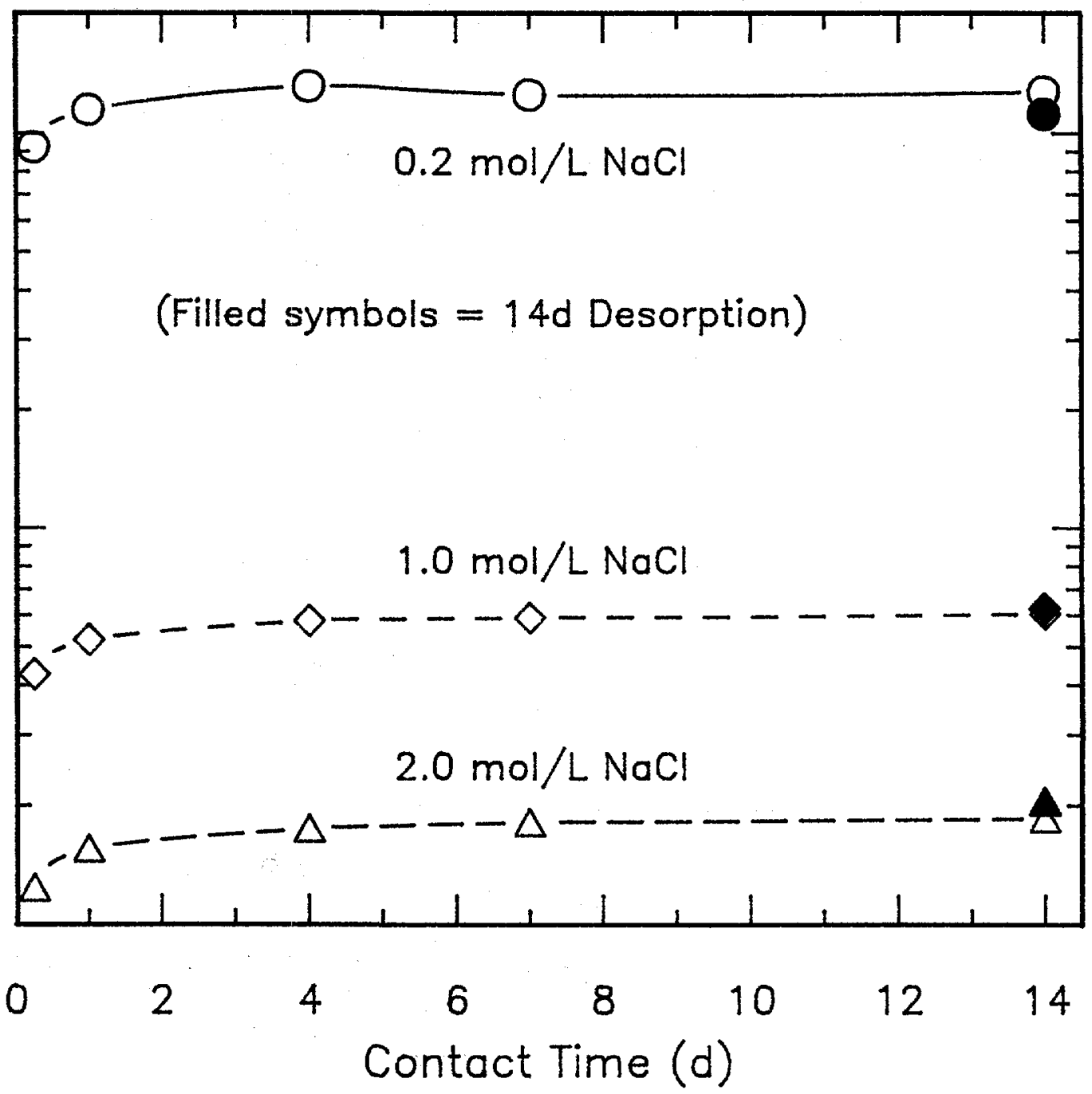

Fig. 1 Sorption and desorption of strontium onto clinoptilolite as a function of contact time. 
Table 4.2. Summary of sorption and desorption results: Sr sorption on Calico Hills Tuff, at various contact times and $\mathrm{NaCl}$ concentrations, followed by two 14-day desorptions

\begin{tabular}{llllllr}
\hline $\begin{array}{c}\text { Contact } \\
\text { Time }\end{array}$ & \multicolumn{7}{c}{$\begin{array}{l}\text { Sorption Ratio Rs, at } \\
\text { Nac1 Concentration (mol/L) }\end{array}$} \\
\cline { 2 - 7 } (d) & 2.00 & Sdev & 1.00 & Sdev & 0.20 & Sdev \\
\hline 0.25 & 3.84 & 0.15 & 12.81 & 0.12 & 283.28 & 11.35 \\
1.00 & 5.88 & 0.11 & 20.06 & 0.31 & 401.18 & 5.08 \\
4.00 & 7.61 & 0.13 & 25.19 & 0.09 & 482.01 & 12.93 \\
7.00 & 7.90 & 0.07 & 26.97 & 0.27 & 532.60 & 29.43 \\
14.00 & 8.44 & 0.16 & 28.16 & 0.14 & 595.43 & 29.28 \\
\hline
\end{tabular}

\begin{tabular}{lllllll}
\hline Sorption & \multicolumn{5}{c}{$\begin{array}{l}\text { FIRST DESORPTION } \\
\text { Contact } \\
\text { Time }\end{array}$} & \multicolumn{5}{c}{$\begin{array}{l}\text { 14-Day Desorption Ratio Rd, } \\
\text { at NaC1 Concentration (mol/L) }\end{array}$} & \\
\cline { 2 - 7 } (d) & 2.00 & Sdev & 1.00 & Sdev & 0.20 & Sdev \\
\hline 0.25 & 9.01 & 0.29 & 29.49 & 0.32 & 574.92 & 29.59 \\
1.00 & 9.07 & 0.25 & 30.11 & 0.10 & 639.75 & 12.42 \\
4.00 & 9.36 & 0.13 & 30.41 & 0.81 & 621.52 & 12.32 \\
7.00 & 9.34 & 0.13 & 30.46 & 0.50 & 555.01 & 34.30 \\
14.00 & 9.94 & 0.20 & 32.36 & 0.57 & 531.19 & 9.91 \\
\hline
\end{tabular}

\begin{tabular}{|c|c|c|c|c|c|c|}
\hline \multirow{2}{*}{$\begin{array}{l}\text { Sorption } \\
\text { Contact } \\
\text { Time } \\
\text { (d) }\end{array}$} & \multicolumn{5}{|c|}{$\begin{array}{l}\text { SECOND DESORPTION } \\
\text { 14-Day Desorption Ratio Rd, } \\
\text { at NaC1 Concentration (mol/L) }\end{array}$} & \multirow{2}{*}{ Sdev } \\
\hline & 2.00 & Sdev & 1.00 & Sdev & 0.20 & \\
\hline 0.25 & 87.92 & 2.87 & 71.53 & 0.55 & 653.22 & 37.14 \\
\hline 1.00 & 64.43 & 1.22 & 58.26 & 0.61 . & 632.09 & 12.47 \\
\hline 4.00 & 52.85 & 1.39 & 52.49 & 0.75 & 615.50 & 38.95 \\
\hline 7.00 & 51.26 & 0.81 & 53.28 & 0.95 & 596.47 & 10.33 \\
\hline 14.00 & 50.12 & 0.45 & 52.56 & 1.26 & 588.67 & 11.58 \\
\hline
\end{tabular}


Sr Sorption on Calico Hills Tuff Effect of Contact Time and $\mathrm{Na}^{+}$Concentration

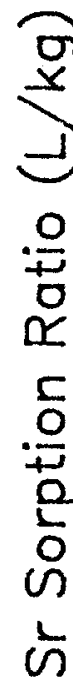

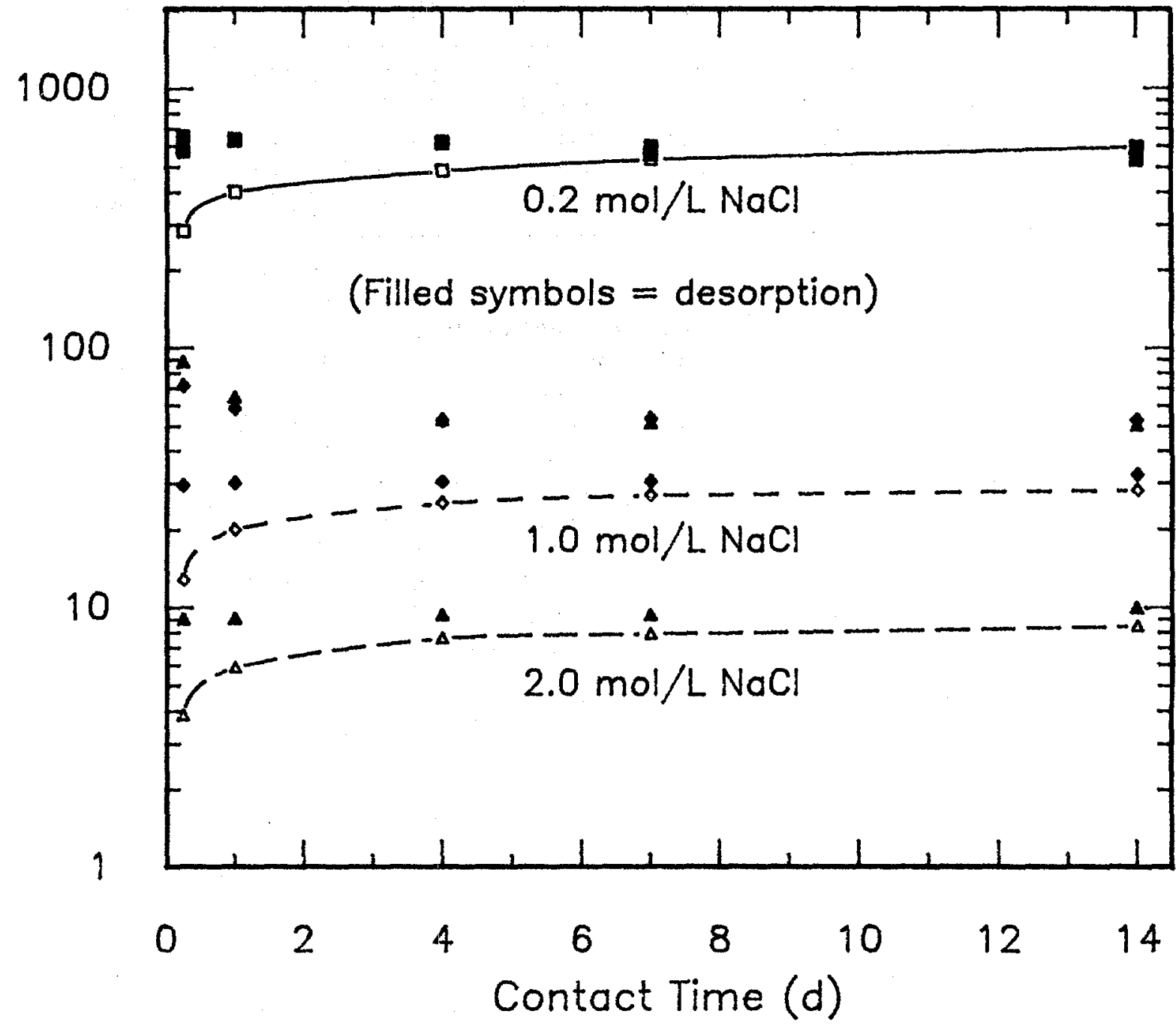

Fig. 2 Sorption and desorption of strontium onto Calico Hills Tuff as a function of contact time. 
Table 4.3. Summary of sorption and desorption results:

Cs sorption on clinoptilolite, at various contact times and $\mathrm{NaCl}$ concentrations, followed by 14 -day desorption

\begin{tabular}{lllllll}
\hline $\begin{array}{c}\text { Contact } \\
\text { Time }\end{array}$ & \multicolumn{7}{c}{$\begin{array}{l}\text { Sorption Ratio Rs, at } \\
\text { NaC1 Concentration (mol/L) }\end{array}$} \\
\cline { 2 - 7 } (d) & 2.00 & Sdev & 1.00 & Sdev & 0.20 & Sdev \\
\hline 0.25 & 174.8 & 3.7 & 403.1 & 26.8 & 2000 & 282 \\
1.00 & 165.9 & 1.1 & 380.2 & 11.6 & 2208 & 169 \\
4.00 & 182.4 & 3.4 & 416.3 & 14.0 & 2166 & 187 \\
7.00 & 182.2 & 4.2 & 429.8 & 19.6 & 2443 & 193 \\
14.00 & 177.0 & 0.3 & 390.1 & 8.2 & 2250 & 484 \\
\hline
\end{tabular}

\begin{tabular}{ccccccc}
\hline $\begin{array}{c}\text { Sorption } \\
\text { Contact } \\
\text { Time }\end{array}$ & \multicolumn{5}{c}{$\begin{array}{l}\text { 14-Day Desorption Ratio Rd, } \\
\text { at NaCl }\end{array}$} \\
\cline { 2 - 7 } (d) & 2.00 & Sdev & 1.00 & Sdev & 0.20 & Sdev \\
\hline 0.25 & 201.3 & 3.9 & 446.4 & 4.2 & 1982 & 114 \\
1.00 & 196.6 & 3.0 & 433.2 & 8.6 & 2199 & 207 \\
4.00 & 199.8 & 2.7 & 459.3 & 24.5 & 2141 & 75 \\
7.00 & 199.5 & 5.9 & 437.8 & 19.6 & 2255 & 193 \\
14.00 & 200.2 & 3.7 & 466.5 & 2.9 & 2207 & 286 \\
\hline
\end{tabular}


Cs Sorption on Clinoptilolite Effect of Contact Time and $\mathrm{Na}^{+}$Concentration

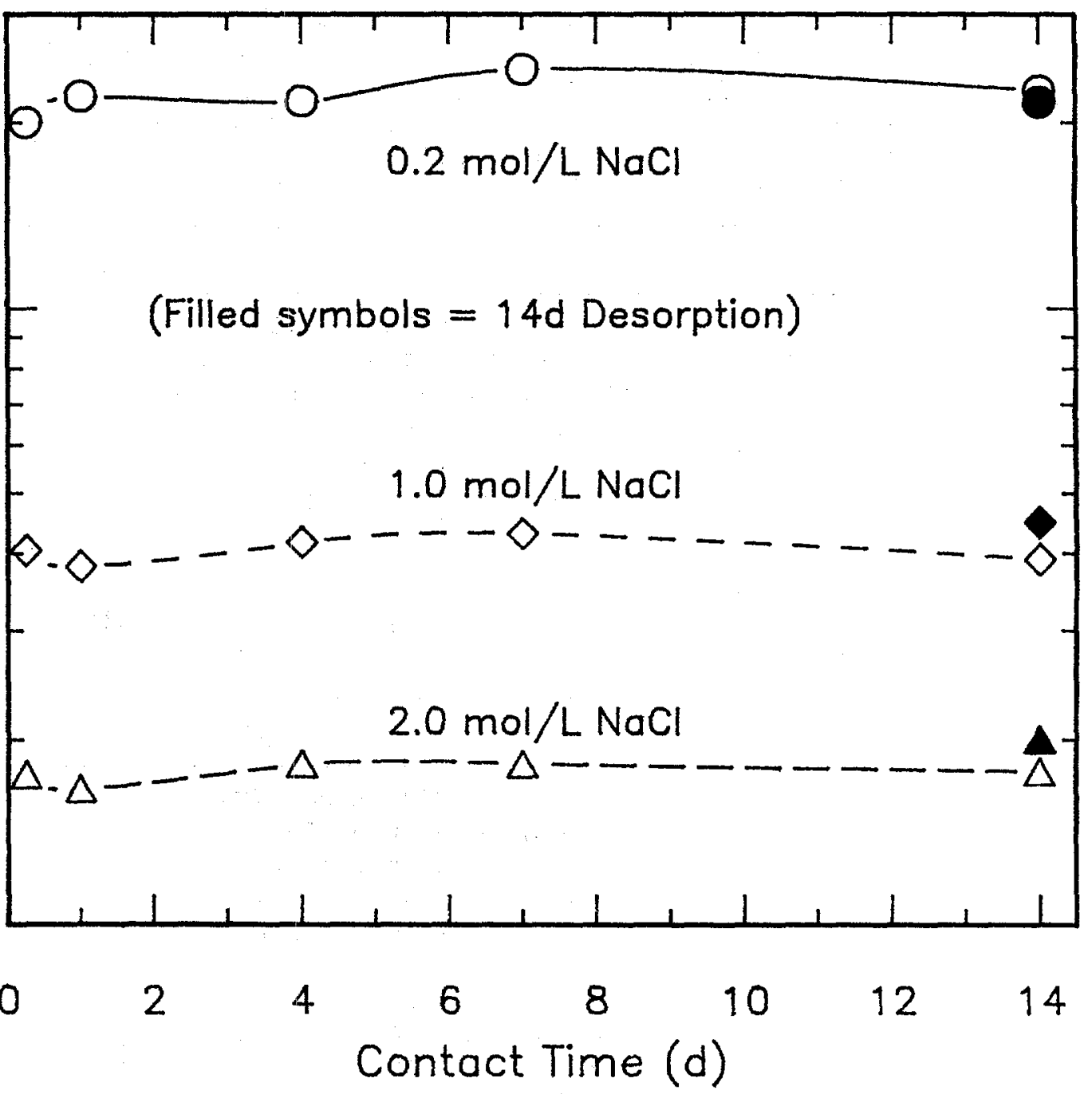

Fig. 3 Sorption and desorption of cesium onto clinoptilolite as a function of contact time. 
Table 4.4. Summary of sorption and desorption results:

Cs sorption on Calico Hills Tuff, at various contact times and $\mathrm{NaCl}$ concentrations, followed by two 14-day desorptions

\begin{tabular}{|c|c|c|c|c|c|c|}
\hline \multirow{2}{*}{$\begin{array}{l}\text { Contact } \\
\text { Time } \\
\text { (d) }\end{array}$} & \multicolumn{5}{|c|}{$\begin{array}{l}\text { Sorption Ratio Rs, at } \\
\mathrm{NaCl} \text { Concentration (mol/L) }\end{array}$} & \multirow[b]{2}{*}{ Sdev } \\
\hline & 2.00 & Sdev & 1.00 & Sdev & 0.20 & \\
\hline 0.25 & 103.6 & 0.9 & 219.3 & 5.1 & 846 & 122 \\
\hline 1.00 & 105.1 & 0.3 & 214.0 & 2.9 & 1064 & 41 \\
\hline 4.00 & 105.2 & 1.1 & 217.1 & 3.3 & 955 & 80 \\
\hline 7.00 & 106.3 & 1.3 & 216.5 & 5.8 & 1037 & 18 \\
\hline 14.00 & 110.8 & 1.1 & 227.0 & 0.3 & 1019 & 39 \\
\hline
\end{tabular}

\begin{tabular}{|c|c|c|c|c|c|c|}
\hline \multirow{2}{*}{$\begin{array}{l}\text { Sorption } \\
\text { Contact } \\
\text { Time } \\
\text { (d) }\end{array}$} & \multicolumn{5}{|c|}{$\begin{array}{l}\text { FIRST DESORPTION } \\
\text { 14-Day Desorption Ratio Rd, } \\
\text { at NaC1 Concentration (mol/L) }\end{array}$} & \multirow{2}{*}{ Sdev } \\
\hline & 2.00 & Sdev & 1.00 & Sdev & 0.20 & \\
\hline 0.25 & 118.2 & 0.8 & 282.7 & 3.6 & 1021 & 84 \\
\hline 1.00 & 107.9 & 0.8 & 204.6 & 6.2 & 1028 & 122 \\
\hline 4.00 & 104.8 & 1.2 & 208.8 & 4.5 & 927 & 48 \\
\hline 7.00 & 105.9 & 2.3 & 202.1 & 3.1 & 949 & 74 \\
\hline 14.00 & 115.3 & 3.7 & 229.6 & 5.9 & 966 & 74 \\
\hline
\end{tabular}

\begin{tabular}{|c|c|c|c|c|c|c|}
\hline \multirow{2}{*}{$\begin{array}{l}\text { Sorption } \\
\text { Contact } \\
\text { Time } \\
\text { (d) }\end{array}$} & \multicolumn{6}{|c|}{$\begin{array}{l}\text { 14-Day Desorption Ratio Rd, } \\
\text { at } \mathrm{NaCl} \text { Concentration (mol/L) }\end{array}$} \\
\hline & 2.00 & Sdev & 1.00 & Sdev & 0.20 & Sdev \\
\hline 0.25 & 131.87 & 2.08 & 245.40 & 6.17 & 946.12 & 83.85 \\
\hline 1.00 & 133.63 & 4.00 & 247.74 & 5.04 & 967.82 & 48.37 \\
\hline 4.00 & 135.91 & 3.07 & 255.12 & 4.67 & 1037.89 & 59.07 \\
\hline 7.00 & 134.21 & 1.46 & 247.28 & 5.92 & 1007.72 & 78.72 \\
\hline 14.00 & 133.60 & 4.89 & 241.67 & 4.84 & 1010.12 & 82.79 \\
\hline
\end{tabular}




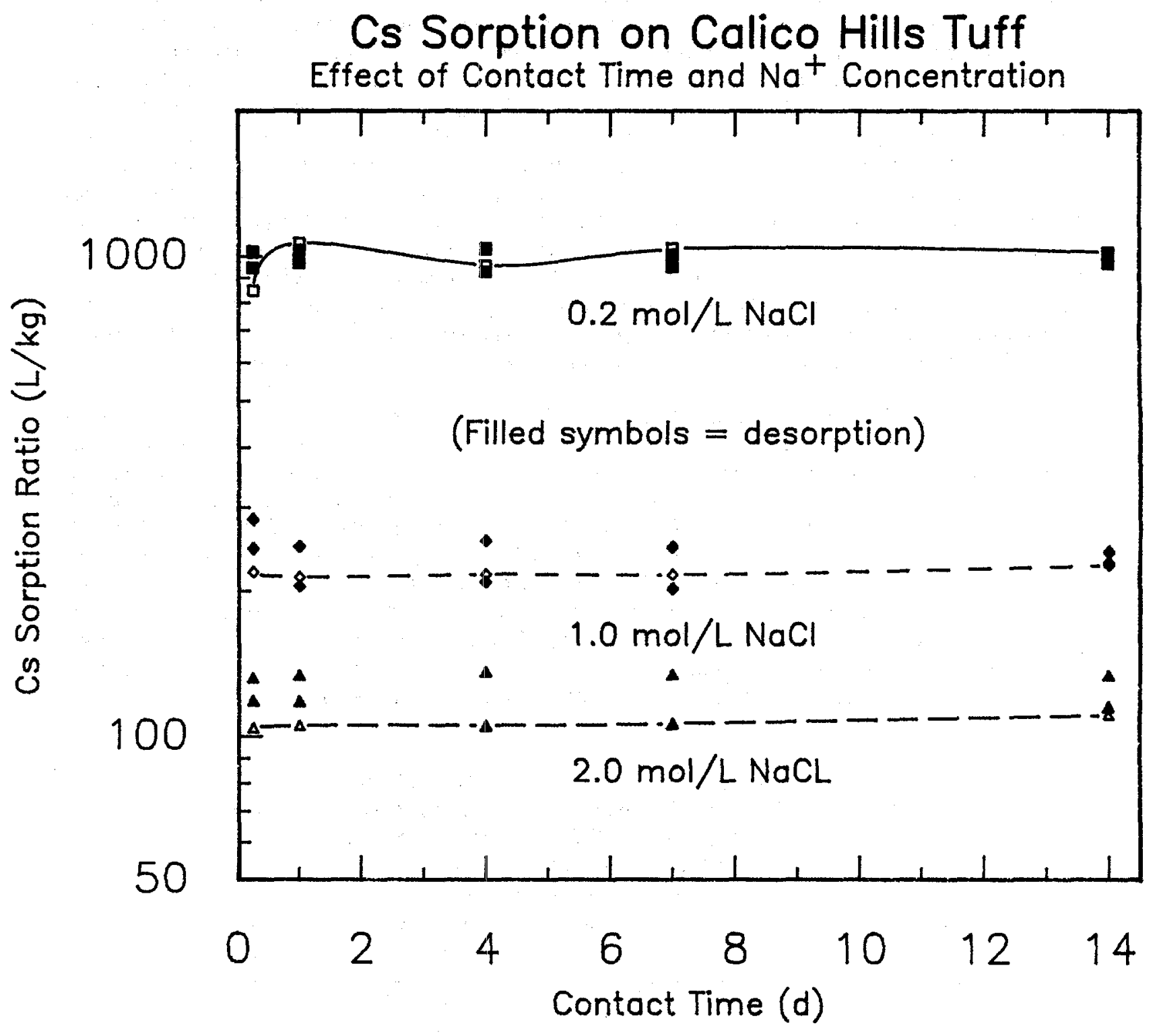

Fig. 4 Sorption and desorption of cesium onto Calico Hills Tuff as a function of contact time. 


\section{DISCUSSION}

The sorption of simple ions on clinoptilolite has been reported and studied as an ion-exchange process (Ames 1960, Ames 1964a, Ames 1964b). In these papers, exchange experiments were described to obtain the thermodynamic equilibrium constants of a number of ion-exchange reactions including those studied here. However, to do this, sorption was not studied at trace loadings as we have done here but at loadings significant with respect to the capacity. Activity coefficient calculations were applied to the equilibrium quotients to obtain the thermodynamic equilibrium constants. If sorption obeys a perfectly linear isotherm from trace loadings to capacity then there should be no difference in the equilibrium constant; however, it remains to be determined whether the isotherms for $\mathrm{Sr}^{2+}$ and $\mathrm{Cs}^{+}$sorption onto our sample of clinoptilolite are linear. Calculation of thermodynamic equilibrium constants or equilibrium quotients from our data requires a knowledge of the capacity of our sample of clinoptilolite, a determination that we have not yet made.

To determine the ideality of the sorption reaction at trace loadings onto clinoptilolite, plots of the logarithms of the sorption ratios vs the logarithms of the concentrations of $\mathrm{Na}^{+}$were made and are shown in Figs. 5 and 6 for strontium and cesium. According to Eq. 2.7, under ideal conditions, plots of this kind should have a slope of -2 for sorption of trace strontium onto the sodium form of clinoptilolite and -1 for the sorption of cesium onto the sodium form of clinoptilolite. Similarly, if the same mechanism is operative with the Calico Hills Tuff, the same slopes should be observed. For the tuff, these plots are shown in Figs. 7 and 8. The values of slopes of the plots in Figs. 5-8 (without any activity coefficient corrections) are shown in Table 5.1.

Table 5.1 Slopes of plots of the logarithms of the sorption ratios of the sorbing ions vs the logarithms of the concentrations of $\mathrm{Na}^{+}$for sorption onto clinoptilolite and Calico Hills Tuff.

\begin{tabular}{lcccc}
\hline $\begin{array}{l}\text { Contact } \\
\text { time (d) }\end{array}$ & $\begin{array}{c}\text { Sr onto } \\
\text { clinopt. }\end{array}$ & $\begin{array}{c}\text { Sr onto } \\
\text { tuff }\end{array}$ & $\begin{array}{c}\text { Cs onto } \\
\text { clinopt. }\end{array}$ & $\begin{array}{c}\text { Cs onto } \\
\text { tuff }\end{array}$ \\
\hline 0.25 & -1.89 & -1.89 & -1.05 & -0.91 \\
1.0 & -1.89 & -1.85 & -1.13 & -1.01 \\
4.0 & -1.90 & -1.82 & -1.07 & -0.95 \\
7.0 & -1.86 & -1.85 & -1.13 & -0.99 \\
14.0 & -1.86 & -1.87 & -1.11 & -0.97 \\
\hline
\end{tabular}

For strontium sorption onto both clinoptilolite and tuff, the slopes vary from -1.82 to -1.90 . At 14 days, which is close to equilibrium, the 


\section{Sr Sorption on Clinoptilolite}

Effect of Contact Time and $\mathrm{Na}^{+}$Concentration

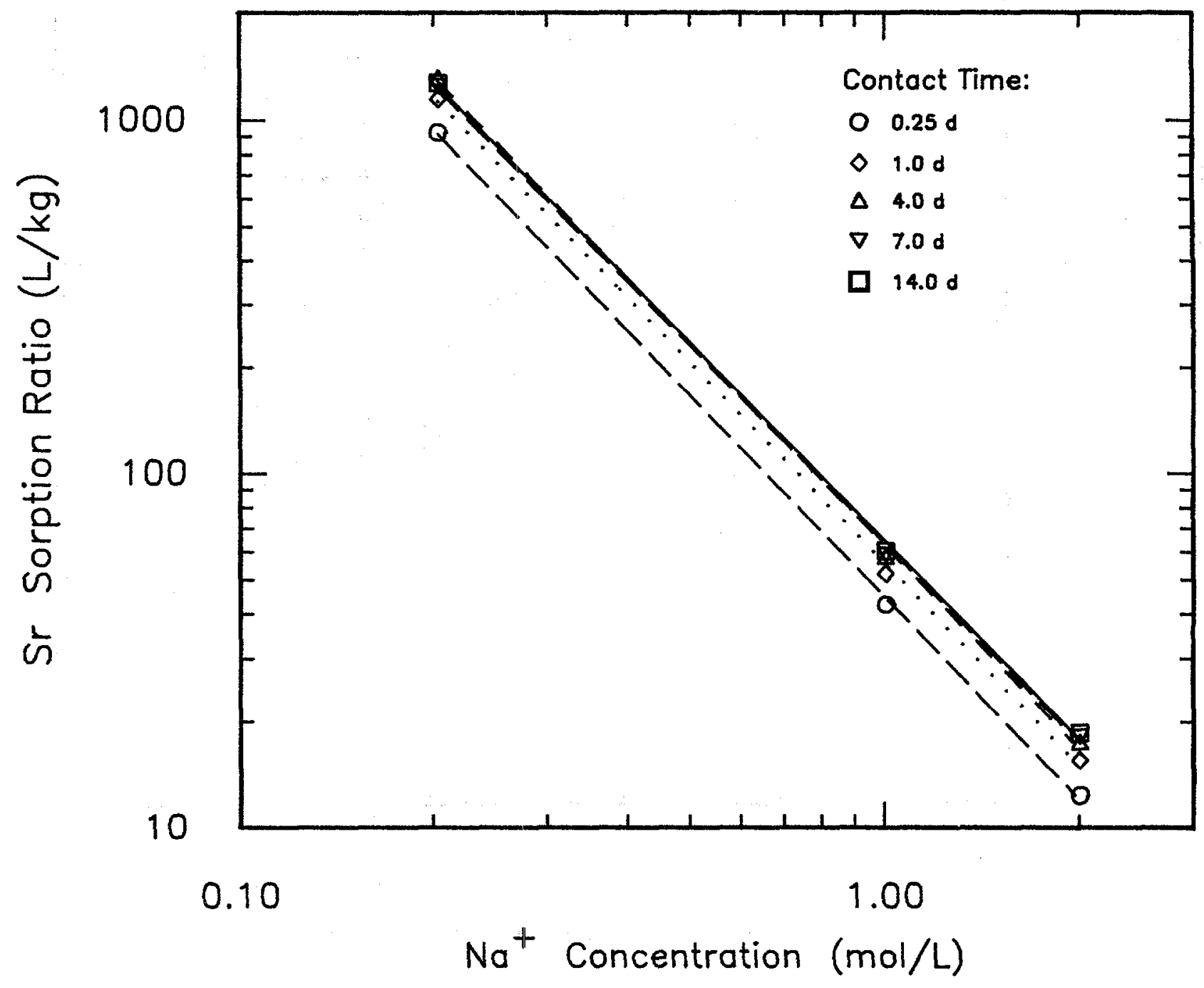

Fig. 5 Plot of the logarithm of the sorption ratio of strontium on clinoptilolite vs the logarithm of the concentration of $\mathrm{Na}^{+}$. 


\section{Sr Sorption on Calico Hills Tuff}

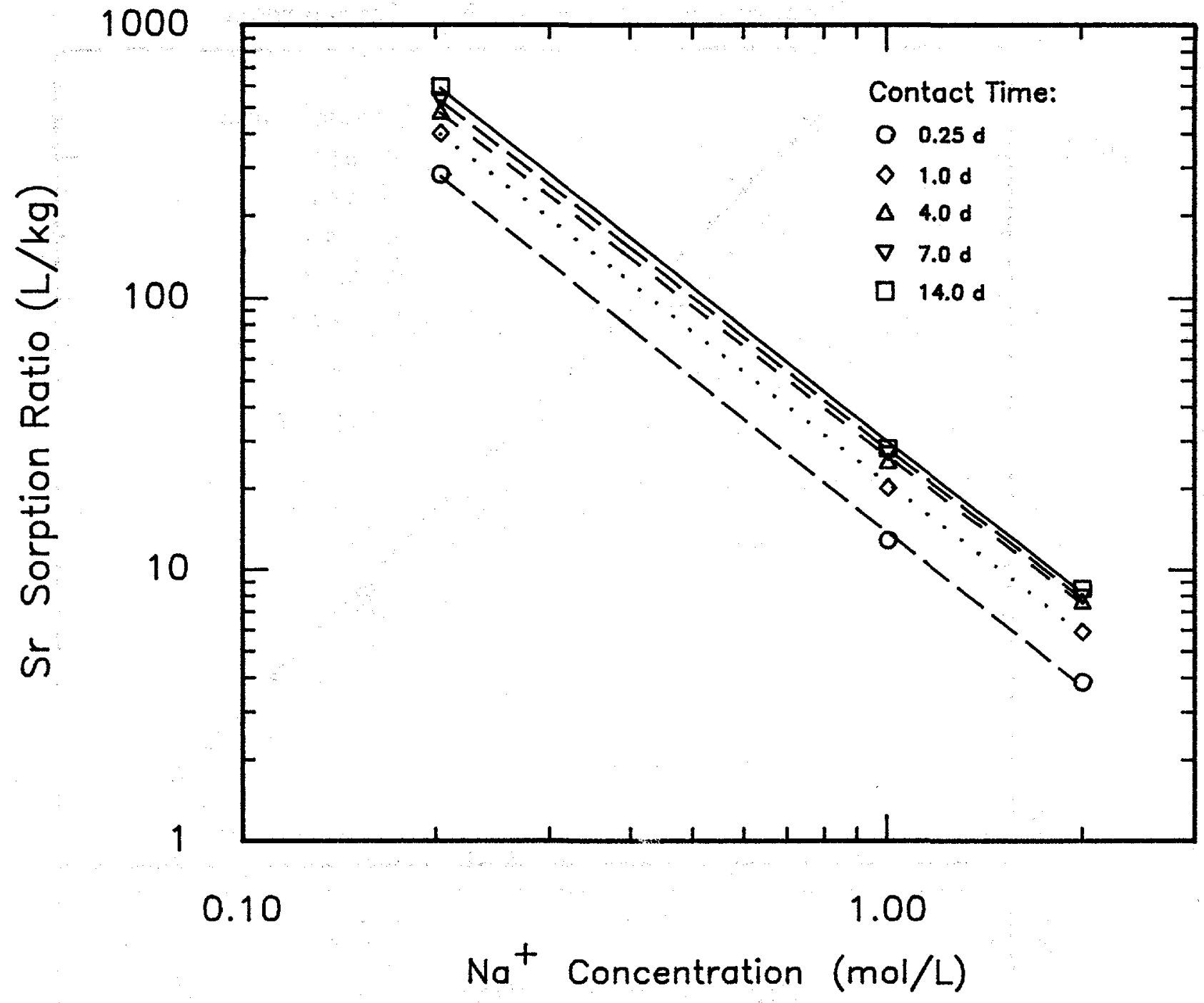

Fig. 6 Plot of the logarithm of the sorption ratio of strontium on Calico Hills Tuff vs the logarithm of the concentration of $\mathrm{Na}^{+}$ 
slopes are virtually identical. This suggests identical ion-exchange reactions on both the tuff and the clinoptilolite. Furthermore it suggests that any sorption on other minerals in the tuff also obeys ionexchange equilibrium equations.

The second desorption experiment on Calico Hills Tuff shown in Fig. 4.2 for strontium showed a more or less constant desorption ratio ranging from 50.12 to $87.92 \mathrm{~L} / \mathrm{kg}$ for the 1.00 - and $2.00-\mathrm{mol} / \mathrm{L} \mathrm{NaCl}$ solutions. For the $0.2-\mathrm{mol} / \mathrm{L}$ solution, there was little difference between the sorption and the two desorption ratios. Thus at $0.2 \mathrm{~mol} / \mathrm{L} \mathrm{NaCl}$ the ion-exchange reaction dominates and because of the higher errors in measurement at these higher sorption and desorption ratios, it is not possible to detect the presence of other sorption processes which may have significant but smaller sorption ratios. However, since the ion-exchange process has much smaller sorption and desorption ratios in the more concentrated $\mathrm{NaCl}$ solutions, another process can more easily be detected. The relatively large values of the second desorption ratio for strontium suggests a strontium fixation process on the clinoptilolite that is not simple ion exchange. Further study would be needed to characterize this reaction.

For cesium sorption onto clinoptilolite and tuff, the slopes show two slightly different patterns in that the slopes for clinoptilolite are somewhat less that -1 (greater in absolute value) and for tuff slightly greater than -1 . These slopes indicate that ion-exchange reactions occur, but there is a small but statistically significant difference in the slopes. At 14 days, which appears to be at or at least near equilibrium, there is an approximately $10 \%$ difference in the slopes for tuff and clinoptilolite. This difference in slopes suggests that another mechanism for sorption may be operative for sorption of cesium on tuff or that there is a small but detectable amount of sorption on one or more other components of the Calico Hills Tuff. To study this reaction further, a sorption isotherm from very low loadings of cesium to the full capacity of the tuff would be desirable. Not only would this experiment indicate the capacity of the tuff for cesium but it would also probably indicate the presence, if any, of other sorbing minerals. In fact, this type of experiment should be done for every sorbing nuclide on the tuffs at the Yucca Mountain site.

Thus, it appears that the sorption reactions of strontium and cesium are mainly exchange reactions on both the tuff and the zeolite, and the sorption reactions appear to have near ideal behavior on the clinoptilolite and only slightly less ideal behavior on the tuff. This is not unexpected for it is known that clinoptilolite is a good ionexchanger and appears to be the principal sorbing mineral in Calico Hills Tuff.

To determine whether the magnitude of the sorption is in proportion to the weight fraction of the clinoptilolite according to Eq. 2.3, plots of the ratio of the overall distribution coefficient to that of clinoptilolite are given in Figs. 9 and 10. As shown above, if only one mineral in a 
mixture sorbs a solution component, then the distribution coefficient of the mixture is simply equal to that of the pure mineral multiplied by its weight fraction. Assuming that all other components of the tuff have negligible sorption, then this relation should apply.

As shown in Figs. 9 and 10, the ratios differ somewhat but with some variations the distribution coefficients for both $\mathrm{Cs}^{+}$and $\mathrm{Sr}^{2+}$ are approximately 508 of that of clinoptilolite. The chip sample of Calico Hills Tuff contained 578 clinoptilolite and a few percent of clay minerals. It is not known whether our sample of the ground tuff (taken from the same core sample) corresponds exactly to $57 \%$ clinoptilolite. This analysis has not yet been done.

There are some differences in the plots in Figs. 9 and 10 for $\mathrm{Cs}^{+}$and $\mathrm{Sr}^{2+}$. For strontium, the plots at 14 days are about the same for the three concentrations of $\mathrm{NaCl}$; for cesium, the plots have similar shapes but with a consistent increase in ratio as the concentration of $\mathrm{NaCl}$ is increased. We conclude therefore that for Calico Hills tuff, there is a very good correlation between sorption ratio and composition when experiments are done in such a way as to make them as similar as possible.

The variations observed among the ratios of the sorption ratios of tuff to those of clinoptilolite can be due in part to experimental errors. However, there are probably also variations due to other sorption processes of smaller magnitude on the tuff and perhaps the clinoptilolite. Similar experiments should be done with other nuclides, particularly those which may not sorb wholly or partly by ion-exchange processes. Perhaps the first element to be studied should be uranium, which could sorb both by ion exchange and by other processes. 


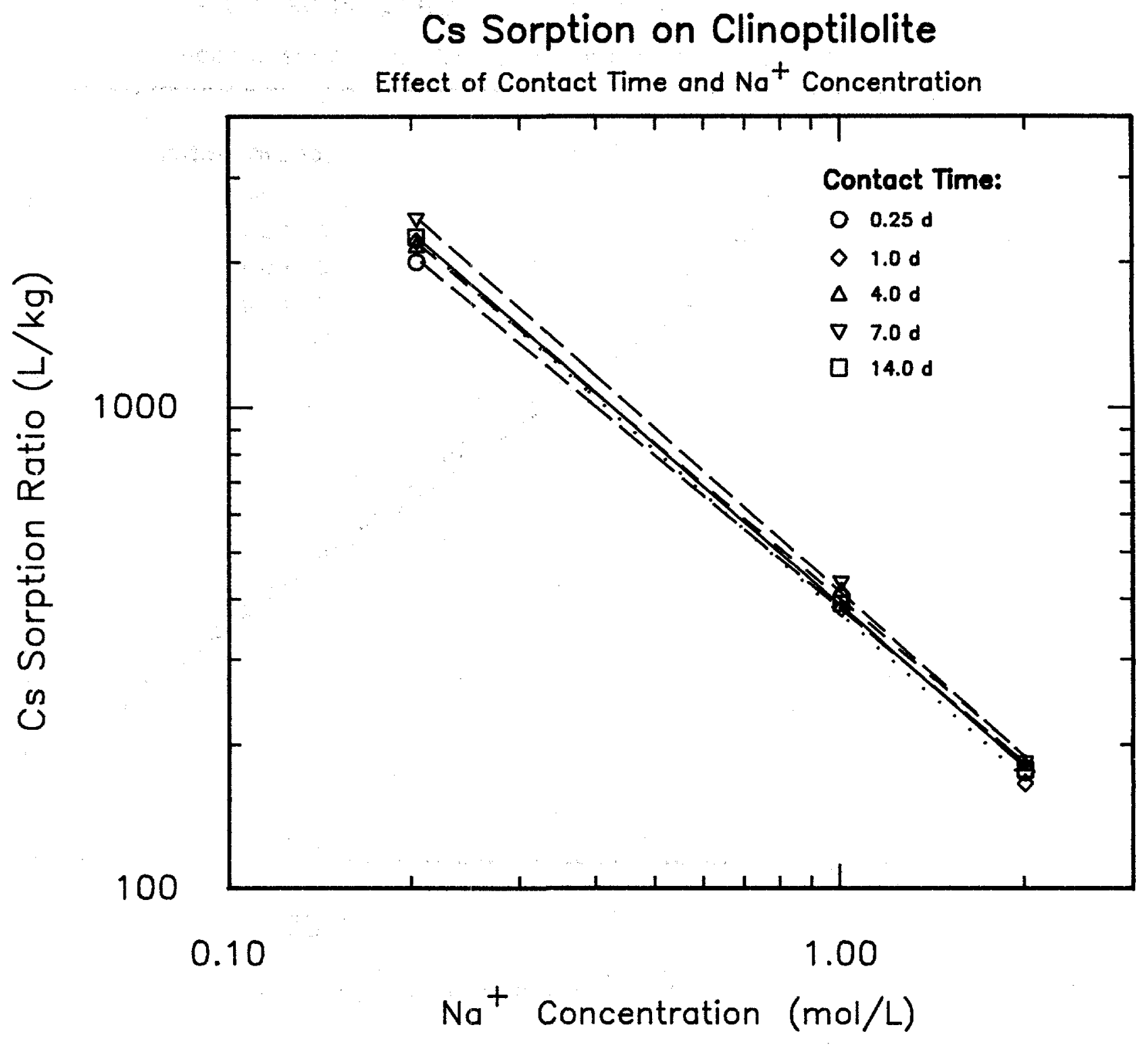

Fig. 7 Plot of the logarithm of the sorption ratio of cesium on clinoptilolite vs the logarithm of the concentration of $\mathrm{Na}^{+}$. 


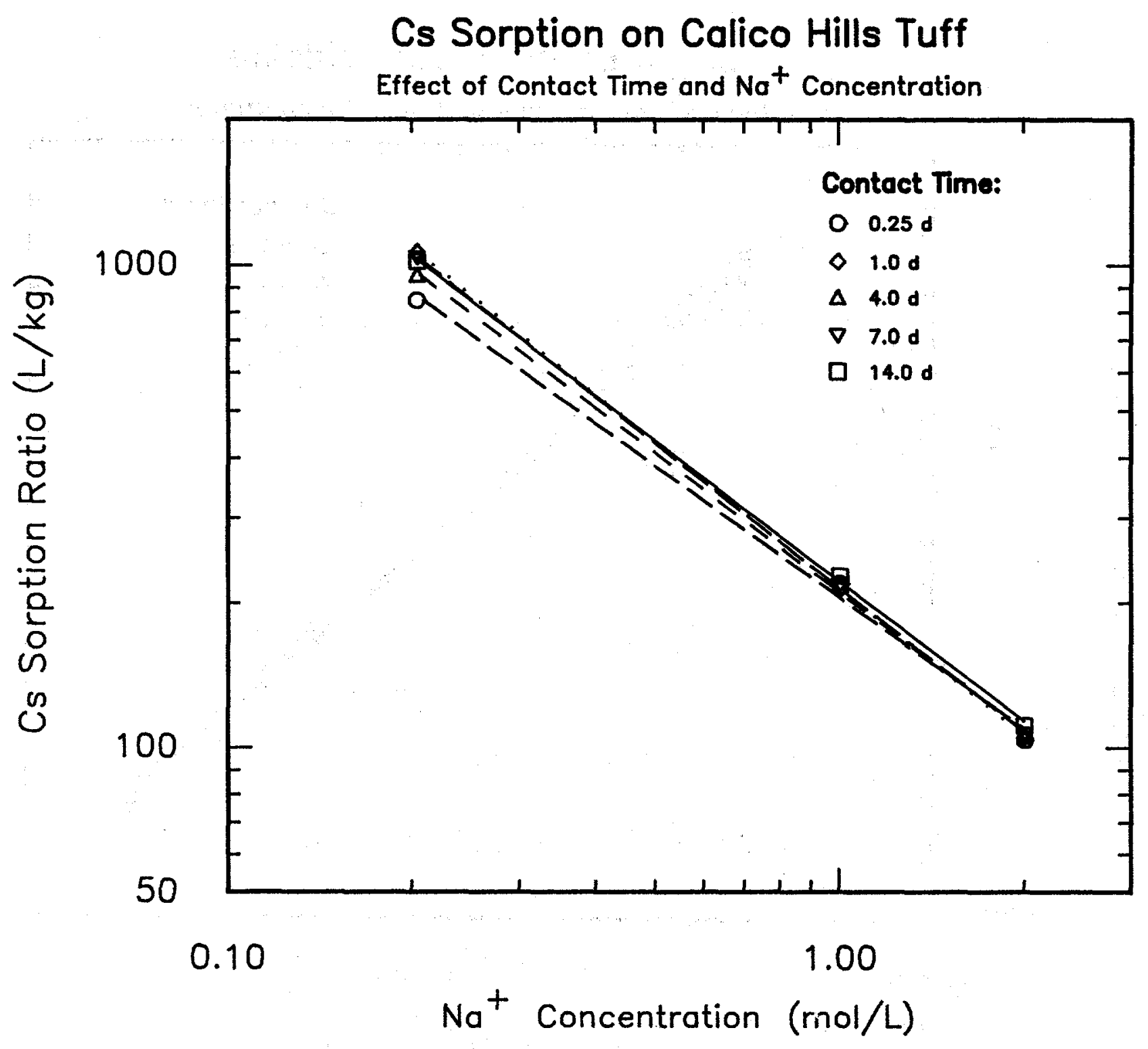

Fig. 8 Plot of the logarithm of the sorption ratio of cesium on Calico Hills Tuff vs the logarithm of the concentration of $\mathrm{Na}^{+}$. 
Ratio of Sr Rs (Tf/Cl)

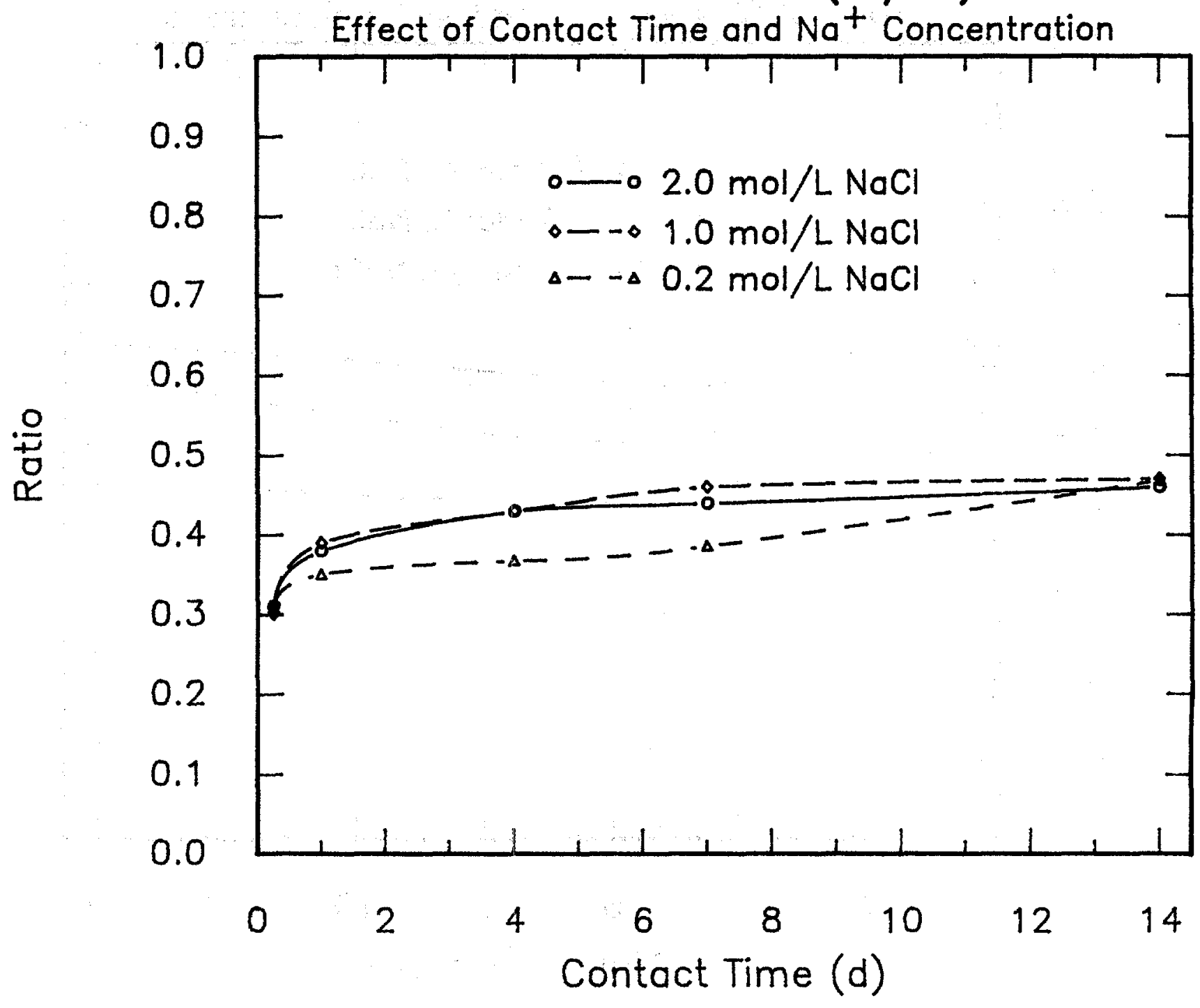

Fig. 9 The ratios of the sorption ratios of strontium on Calico Hills Tuff to the sorption ratios on clinoptilolite as a function of contact time at various concentrations of $\mathrm{Na}^{+}$. 
Ratio of Cs Rs (Tf/Cl)

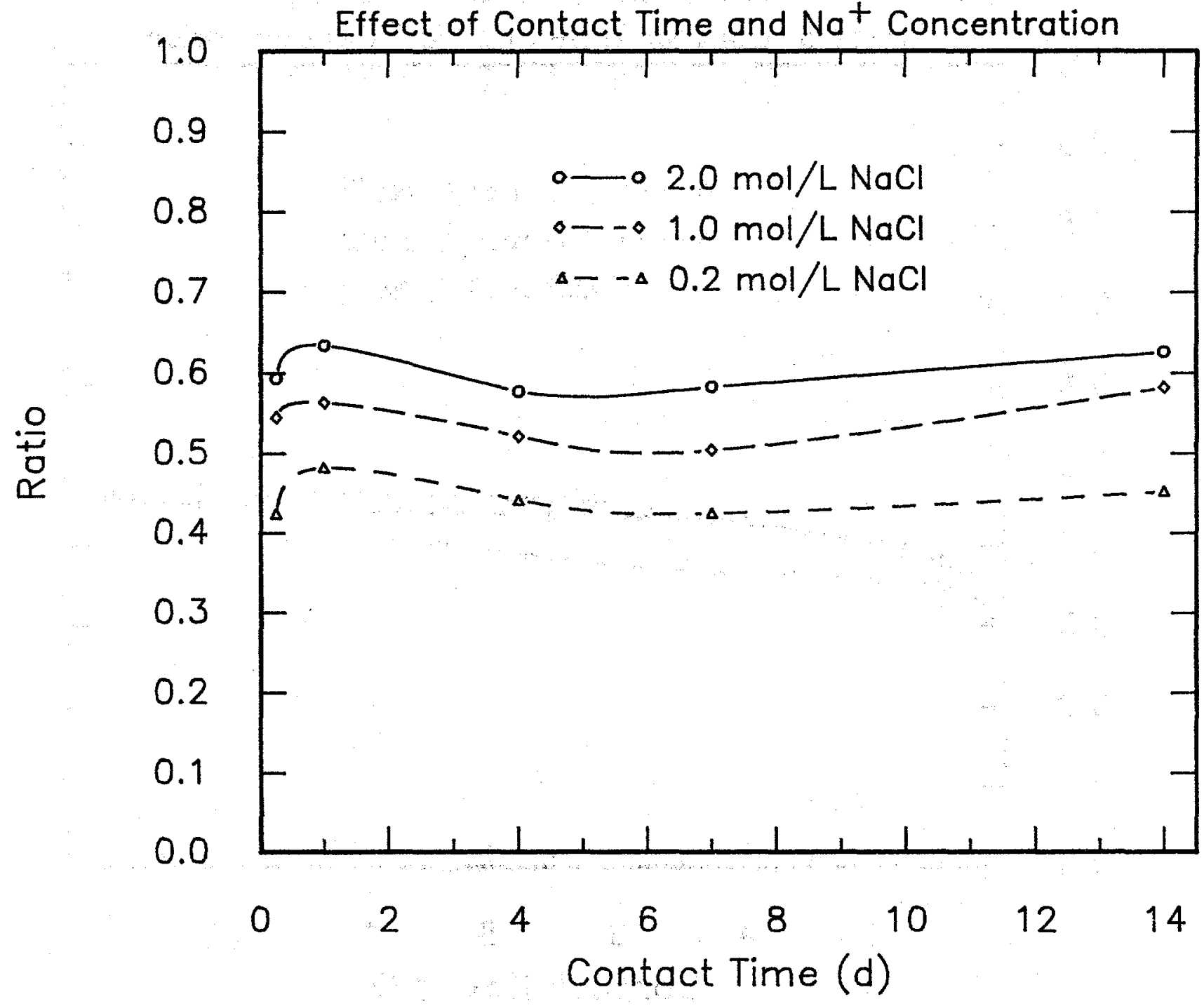

Fig. 10 The ratios of the sorption ratios of cesium on Calico Hills Tuff to the sorption ratios on clinoptilolite as a function of contact time at various concentrations of $\mathrm{Na}^{+}$. 


\section{REFERENCES}

Ames, L. L., Jr., 1960. "The Cation Sieve Properties of Clinoptilolite," The American Mineralogist, 46, 689-700.

Ames, L. L., Jr., 1964a. "Some Zeolite Equilibria with Alkali Metal Cations," The American Mineralogist, 49, 127-145.

Ames, L. L. Jr., 1964b. "Some Zeolite Equilibria with Alkaline Earth Metal Cations," The American Mineralogist, 49, 1099-1110.

Bunzl, $\mathrm{K}$ and $\mathrm{W}$. Schultz, 1980. "Competitive Sorption of $\mathrm{Pb}$ by Bentonite and Sphagnum Peat," Zeitschrift für Pflanzenernährung und Bodenkunde, 143, 182 193.

Daniels, W. R., K. Wolfsberg, R. S. Rundberg, A. E. Ogard, J. F. Kerrisk, C. J. Duffy, T. W. Newton, S. D. Knight, F. O. Lawrence, V. L. Rundberg, M. Sykes, G. Thompson, B. Travis, E. Treher, R. Vidale, G. Walter, R. Aguilar, M. Cisneros, S. Maestas, A. Mitche11, P. Oliver, N. Raybold, and P. Wanek, 1982. Summary Report on the Geochemistry of Yucca Mountain and Evirons, LA-9328-MS, Los Alamos National Laboratory, Los Alamos, NM.

DOE 1986. Nuclear Waste Policy Act (Section 112), Environmental Assessment, Yucca Mountain Site, Nevada Research and Development Area, Nevada, DOE/RW0073, (Vol. 2), U. S. Department of Energy, Office of Civilian Radioactive Waste Management, Washington, DC.

Meyer, R. E., W. D. Arnold, J. G. Blencoe, G. K. Jacobs, A. D. Kelmers, F. G. Seeley, and S. K. Whatley, 1986. Progress in Evaluation of Radionuclide Geochemical Information Developed by DOE High-Leve1 Nuclear Waste Site Projects: Annual Report for October 1984-September 1985, NUREG/CR-4236, Vol 4, ORNL/TM 9614, Oak Ridge National Laboratory, Oak Ridge, TN.

Meyer, R. E., W. D. Arnold, J. G. Blencoe, G. D. O'Kelley, F. I. Case, 1987. Progress in Evaluation of Radionuclide Information Developed by DOE HighLevel Nuclear Waste Repository Site Projects: Semiannual Report for October 1985-March 1986, NUREG/CR-4708, ORNL/TM10147, Vol. 1, No. 1, Oak Ridge National Laboratory, Oak Ridge, TN.

Ogard, A. E. and D. T. Vaniman, Compilers, 1985. Research and Development Activities Related to the Nevada Waste Storage Investigations, July 1September 30, 1984, LA-10299-PR, Los Alamos National Laboratory, Los Alamos, NM.

Palmer, D. A., S. Y. Shiao, R. E. Meyer, and J. A. Wethington, 1981. "Adsorption of Nuclides on Mixtures of Minerals," J. Inorg. Nucl. Chem. 43, 3317-3322. 
Thomas, K. W., 1987. Summary of Sorption Measurements Performed with Yucca Mountain. Nevada. Tuff Samples and Water from Wel1 J-13, LA-10960-MS, Los Alamos National Laboratory, Los Alamos, NM.

Tien, P. L., M. D. Siege1, C. D. Updegraff, K. K. Wahl, and R. V. Guzowski, 1985. Repository Site Data Report for Unsaturated Tuff. Yucca Mountain. Nevada, NUREG/CR-4110, SAND84-2668, Sandia National Laboratories, Albuquerque, NM.

Triolo, R, and M. H. Lietzke, 1980. "Adsorption on Mixtures of Ion Exchangers," J. Inorg. Nuc1. Chem. 42, 913-917. 
(See instructions on the reverse)

NUREG/CR-5463

ORNL-6589

2. TITLE AND SUBTITLE

EFFECTS OF MINERALOGY ON SORPTION OF STRONTIUM AND CESIUM ONTO CALICO HILLS TUFF

3. DATE REPORT PUBLISHED

MONTH April 1990

4. FIN OR GRANT NUMBER B0462

5. AUTHOR(S)

R. E. Meyer, W. D. Arnold, F. I. Case, G. D. O'Re1ley, J. F. Land

Topical Report

7. PERIOD COVERED //nclusive Dates'

8. PERFORMING ORGANIZATION - NAME AND ADDRESS II NRC, provide Division, Office or Region, U.S. Nuclear Regulatory Commission, and majifing adidress; if contractor, provide name and mailing address.)

Oak Ridge National Laboratory

PO Box 2008

Oak Ridge, TN 37831-6201

9. SPONSORING ORGANIZATION - NAME AND ADDRESS Itt NRC, tvpe "Same as above": if comtractor, provide NRC Division, Office or Region, U.S. Nuclear Regulatory Commission, and mailing address.)

\section{Division of Engineering}

Office of Nuclear Regulatory Research

U.S. Nuclear Regulatory Commission

Washington DC 20555

10. SUPPLEMENTARY NOTES

11. ABSTRACT (200 words or less)

Sorption and desorption measurements were made of strontium and cesium onto clinoptilolite and Calico Hills Tuff. The object was to see whether there was a correlation between sorption of strontium and cesium onto Calico Hills Tuff and the sorption of strontium and cesium onto clinoptilolite based on the content of clinoptilolite in the Calico Hills Tuff. If sorption onto Calico Hills Tuff is solely due to the presence of clinoptilolite, then the ratios of the sorption ratios on tuff to those on clinoptilolite at similar conditions should be the weight fraction of the clinoptilolite on the tuff. Since the tuff contained about $50 \%$ clinoptilolite, the ratios would be expected to be about 0.5 if sorption was due solely to slinoptilolite. The experimental evidence showed that the ratios were generally near 0.5 for both cesium and strontium sorption and that ion-exchange processes were operative for both the clinoptilolite and the tuff. However, the ratios differed to a small extent for the different conditions, and there were indications that other sorption processes were involved.

12. KEY WORDS/DESCR:PTORS (List words or phrases that will assist researchers in locating the report.)

\begin{tabular}{|c|}
\hline $\begin{array}{l}\text { 13. AVAILABILITY STATEMENT } \\
\text { un1imited }\end{array}$ \\
\hline 14. SECURITY CLASSIFICATION \\
\hline $\begin{array}{l}\text { TThis Pagel } \\
\text { unclassified }\end{array}$ \\
\hline $\begin{array}{l}\text { IThis Report } \\
\text { unclassified }\end{array}$ \\
\hline 15. NUMBER OF PAGES \\
\hline 16. PRICE \\
\hline
\end{tabular}

Clinoptilolite

Calico Hills Tuff

Ion Exchange
Strontium

Cesium

Sorption 